\title{
SUICIDALITY IN INDIVIDUALS WITH SCHIZOID PERSONALITY DISORDER OR TRAITS: A CLINICAL MINI-REVIEW OF A PROBABLY UNDERESTIMATED ISSUE
}

\author{
Luigi Attademo ${ }^{1}$, Francesco Bernardini ${ }^{2} \&$ Roberta Spatuzzi $^{3}$ \\ ${ }^{1}$ Psychiatric Inpatient Unit, Department of Mental Health, ASP Basilicata, Potenza, Italy \\ ${ }^{2}$ Psychiatric Inpatient Unit, Department of Mental Health, AsFO Friuli Occidentale, Pordenone, Italy \\ ${ }^{3}$ Community Mental Health Service, Department of Mental Health, ASP Basilicata, Potenza, Italy \\ received: 10.3.2021; \\ revised: 14.5.2021; \\ accepted: $10,6.2021$
}

\begin{abstract}
SUMMARY
Schizoid personality disorder (SZPD) is a Cluster A personality disorder whose essential feature is a lifelong pattern of detachment from social relationships and a restricted range of emotional expression. Although SZPD has been in every edition of the Diagnostic and Statistical Manual of Mental Disorders, empirical research on this disorder is actually limited, due to the fact that SZPD is rarely encountered in clinical settings. In fact, individuals with SZPD rarely present for treatment, as their isolation is often ego-syntonic; therefore, the prevalence of SZPD is not clearly established. Suicide ideation may be a running theme for individuals with SZPD. However, suicidality in SZPD is actually an underestimated topic. Aiming to draw more attention to this underestimated issue, with this paper the authors intend to provide a list of studies on suicidality in individuals with SZPD or traits, in the form of a clinical mini-review. Reported studies show that an underlying SZPD, or the presence of schizoid traits too, appear to be definitely a major risk factor for completed suicide and serious suicide attempts. This maladaptive personality disorder seems to not allow the individual to ask for help and to deny him the comforts of intimacy. Therefore, clinicians should be aware that schizoid traits suchs as solitary lifestyle, loneliness, emotional detachment, and impaired communication ability, are features associated with a vulnerability to suicidal behavior. We recommend the clinical assessment of this symptoms' constellation, in order to address patients with SZPD to most proper treatment.
\end{abstract}

Key words: attempted suicide, mini-review, schizoid personality disorder, suicidal ideation, suicide

\section{INTRODUCTION}

Schizoid personality disorder (SZPD) is a Cluster A personality disorder whose essential feature is a lifelong pattern of detachment from social relationships and a restricted range of emotional expression (American Psychiatric Association (APA) 2013).

The adjective "schizoid" was originally coined by Bleuler to designate a component of man's personality that directed his attention toward his own inner life (and away from the external world). A morbid - not psychotic - exaggeration of this disposition was named "schizoid personality" (Akhtar 1987). Later, the term "schizoid" was also used to describe, for example, the prodromal seclusiveness and isolation frequently observed in individuals with schizophrenia (Fariba \& Gupta 2020).

Although SZPD has been in every edition of the Diagnostic and Statistical Manual of Mental Disorders (DSM), empirical research on this disorder is actually limited, due in part to a research interest shift from SZPD to the schizotypal personality disorder after the DSM-III publication and, in particular, to the fact that SZPD is rarely encountered in clinical settings. In fact, individuals with SZPD rarely present for treatment, as their isolation is often ego-syntonic (Widiger \& Rojas 2015). An individual with SZPD will unlikely present in the clinical setting voluntarily, unless prompted by a family member, or as a result of a comorbid disorder (Fariba \& Gupta 2020).

For the above reasons, the prevalence of SZPD is not clearly established. The mean and median prevalence of SZPD seem to be $1.3 \%$ and $0.9 \%$, respectively, with a range of $0 \%$ to $5.7 \%$ as found in different epidemiological studies. SZPD or schizoid traits are: a) diagnosed slightly more often in males, b) related to lower education and socioeconomic status, and to a higher risk for homelessness, and c) related to poor quality of life and dysfunction (APA 2013, Morgan \& Zimmerman 2018, Oldham et al. 2014, Widiger \& Rojas 2015).

Shyness/introversion, seclusiveness, eccessive daydreaming, autistic thinking, avoidance of close or competitive relationships, discomfort with human interaction, and flattened/constricted affect are noteworthy and appear to worsen with age in individuals affected. They experience little pleasure in life (anhedonia) and are generally emotionally detached, appearing cold and aloof (Morgan \& Zimmerman 2018, Oldham et al. 2014, Widiger \& Rojas 2015).

Although SZPD appears uncommon in clinical populations, individuals with this disorder suffer a lot. In fact, it has been suggested that underlying all of this apparent detachment is an intense neediness for others (Oldham et al. 2014). 
Table 1. Studies on suicidality in individuals with schizoid personality disorder or traits

\begin{tabular}{|c|c|c|}
\hline Authors and year & Sample characteristics & Comments \\
\hline $\begin{array}{l}\text { Levi-Belz } \\
\text { et al. } 2019\end{array}$ & $\begin{array}{l}338 \text { Participants divided into four groups } \\
\text { (78 medically serious suicide attempters, } \\
116 \text { medically non-serious suicide attempters, } \\
47 \text { psychiatric controls, } 97 \mathrm{HCs} \text { ) } \\
197 \mathrm{M}, 141 \mathrm{~F} \\
\text { Age } 19-85 \\
\text { Country: Israel } \\
\text { Setting: clinical; inpatients }\end{array}$ & $\begin{array}{l}\text { Suicide attempters showed higher levels of most } \\
\text { SPZD symptoms (Wilks F approximation } \\
\left.(21,933)=2.52 \mathrm{~s}, \mathrm{p}<0.001, \mathrm{Eta}^{2}=0.07\right) \text {. Solitary } \\
\text { lifestyle and emotional detachment were higher } \\
\text { among medically serious suicide attempters } \\
\text { relative to less-serious attempters. Emotional } \\
\text { detachment doubled the risk for high lethality } \\
(\mathrm{p}=0.002, \mathrm{OR}=1.913, \mathrm{CI}=1.25-2.79) .\end{array}$ \\
\hline $\begin{array}{l}\text { Canal-Rivero } \\
\text { et al. } 2017\end{array}$ & $\begin{array}{l}65 \text { FEP patients } \\
44 \mathrm{M}, 21 \mathrm{~F} \\
\text { Age } 14-54 \\
\text { Country: Spain }\end{array}$ & $\begin{array}{l}\text { Premorbid SZPD symptoms emerged as } \\
\text { predictors of suicide attempts occurred over the } \\
12 \text { months after FEP ( } p=0.04, \mathrm{OR}=1.62,95 \% \\
\mathrm{CI}=1.02-2.57) \text {. }\end{array}$ \\
\hline
\end{tabular}

Gesi et al. $2016 \quad 145$ BD-I or MDD patients

$54 \mathrm{M}, 91 \mathrm{~F}$

Age 18-60

Country: Italy

Setting: clinical; out- and inpatients

Del Bello

38 Patients divided into two groups

et al. 2015

(15 with non-fatal suicidal behaviors,

23 with self-injurious behaviors)

M 22, F 16

Age 23-85

Country: Italy

Setting: clinical; inpatients

Levi-Belz et al. 336 Participants divided into four groups

2014

(78 medically serious suicide attempters,

116 medically non-serious suicide attempters,

47 psychiatric controls, $95 \mathrm{HCs}$ )

$161 \mathrm{M}, 175 \mathrm{~F}$

Age 20-85

Country: Israel

Setting: clinical; inpatients

Gvion 196 Participants divided into four groups

et al. 2014 (43 medically serious suicide attempters,

49 medically non-serious suicide attempters,

47 psychiatric controls, $57 \mathrm{HCs}$ )

$124 \mathrm{M}, 72 \mathrm{~F}$

Age 16-71

Country: Israel

Setting: clinical; inpatients

Horesh 102 Participants divided into two groups

et al. $2012 \quad$ (35 medically serious suicide attempters,

67 medically non-serious suicide attempters)

The presence of SZPD symptoms were associated with lifetime suicidality $(\beta=0.228$, $\mathrm{p}=0.007)$.

SZPD was significantly related to non-fatal suicidal behaviors and thoughts $(\mathrm{p}=0.042)$.

Medically serious suicide attempters had significantly more SZPD symptoms and loneliness than the other three groups $(\mathrm{p}<0.05)$. SZPD symptoms were correlated to higher letality of the suicide attempt $(\mathrm{r}=0.36, \mathrm{p}<0.001)$.

Medically serious suicide attempters had significantly more SZPD symptoms $(\mathrm{p}<0.001)$ and loneliness than the other three groups. SZPD symptoms were correlated to higher letality of the suicide attempt.

$49 \mathrm{M}, 53 \mathrm{~F}$

Age 20-85

Country: Israel

Setting: clinical; inpatients

Bolton

et al. 2010
5972 MDD patients divided into two groups

(169 with a history of suicide attempt, 5803 without a history of suicide attemp)

Gender not reported

Age $\geq 18$

Country: USA

Setting: non-clinical; non-institutionalized, civilian population

Legend: BD-I: bipolar I disorder; F: females; FEP: first episode psychosis; HCs: healthy controls; M: males;

MCMI: Millon Clinical Multiaxial Inventory; MDD: major depressive disorder; SZPD: schizoid personality disorder 
Table 1. Continues

\begin{tabular}{|c|c|}
\hline Authors and year & Sample characteristics \\
\hline Levi et al. 2008 & $\begin{array}{l}173 \text { Participants divided into three groups } \\
\text { (35 medically serious suicide attempters, } 67 \mathrm{me}- \\
\text { dically non-serious suicide attempters, } 61 \mathrm{HCs} \text { ) } \\
86 \mathrm{M}, 87 \mathrm{~F} \\
\text { Age } 20-85 \\
\text { Country: Israel } \\
\text { Setting: clinical; inpatients }\end{array}$ \\
\hline $\begin{array}{l}\text { Pompili } \\
\text { et al. } 2008\end{array}$ & $\begin{array}{l}150 \text { Psychiatric patients } \\
50 \mathrm{M}, 100 \mathrm{~F} \\
\text { Mean age } 39 \mathrm{M}, 43 \mathrm{~F} \\
\text { Country: Italy } \\
\text { Setting: clinical; inpatients }\end{array}$ \\
\hline $\begin{array}{l}\text { Craig \& Bivens } \\
2000\end{array}$ & $\begin{array}{l}408 \text { Patients with substance use disorder divided } \\
\text { into two group ( } 68 \text { with a history of suicide } \\
\text { attempt, } 340 \text { without a history of suicide attempt) } \\
408 \mathrm{M}, 0 \mathrm{~F} \text {; Age not reported } \\
\text { Country: USA } \\
\text { Setting: clinical; inpatients }\end{array}$ \\
\hline
\end{tabular}

Ellis

et al. 1996

299 Psychiatric patients with a history of suicide attempt or ideation

Gender not reported; Age 18-37

Country: USA

Setting: clinical; outpatients

Lesage

et al. 1994

150 Participants divided into two groups

(75 Cases dead by suicide, 75 Controls)

$150 \mathrm{M}, 0 \mathrm{~F}$

Age 18-35

Country: Canada

Setting: non-clinical

Apter et al. 199343 Soldiers dead by suicide

$43 \mathrm{M}, 0 \mathrm{~F}$

Age 18-21

Country: Israel

Setting: non-clinical

Wolff 1992283 Participants divided into two group

(141 Patients with SZPD, 142 Controls)

219 M, 64 F; Mean age 26

Country: Scotland

Setting: clinical; outpatients

McCann \& Suess 35 Psychiatric patients with a "Negativistic1988

Avoidant-Schizoid" MCMI profile

$19 \mathrm{M}, 16 \mathrm{~F}$

Age not reported

Country: USA

Setting: clinical; inpatients

Goldney $1981 \quad 110$ Patients who attempted suicide

$0 \mathrm{M}, 110 \mathrm{~F}$

Age 18-30

Country: Australia

Setting: clinical; inpatients

Gupta \& Singh 100 Patients who attempted suicide

1981

$59 \mathrm{M}, 41 \mathrm{~F}$

Age 15-34

Country: India

Setting: clinical; inpatients

\section{Comments}

Communication problems, defined by low selfdisclosure, loneliness, and SZPD symptoms $(\mathrm{p}<0.05, \mathrm{~B}=0.17)$, differentiated medically serious from medically non-serious suicide attempters.

Patients at risk of suicide were more socially introverted, depressed and used schizoid defense mechanisms more often $(\mathrm{p}=0.03, \mathrm{OR}=1.03,95 \%$ CI 1.00-1.07).

Patients with reported prior suicide attempts had significantly higher SZPD symptoms $(\mathrm{p}=0.001)$.

Cluster analysis found that the most representative one was "Negativistic-AvoidantSchizoid".

A clinical postmortem study found that $6.7 \%$ of men dead by suicide met criteria for SZPD.

A clinical postmortem study found that $37 \%$ of the soldiers was classified as having SZPD.

The risk for death by suicide was significantly higher within the schizoid group.

$85 \%$ of the inpatients reported suicidal ideation and $65 \%$ had made a suicide attempt.

Women whose suicide attempts resulted in the greatest risk to life more often demonstrated SZPD symptoms $(\mathrm{p}<0.1)$.

$23 \%$ of the patients had SZPD, with males exhibiting more frequently SZPD symptoms than females.

Legend: BD-I: bipolar I disorder; F: females; FEP: first episode psychosis; HCs: healthy controls; M: males;

MCMI: Millon Clinical Multiaxial Inventory; MDD: major depressive disorder; SZPD: schizoid personality disorder 
Suicide ideation may be a running theme for individuals with SZPD, although they are not likely to actually attempt suicide. The idea of suicide functions like a driving force against the person's schizoid defenses (Masterson \& Klein 1995).

\section{METHODS}

In this mini-review article, we provide a list of studies on suicidality in individuals with schizoid personality disorder or traits, in order to draw more attention to this underestimated topic.

For this reason, we searched the Pubmed electronic database for all articles up to November 11, 2020. Search terms included: ("schizoid" or "schizoid personality" or "schizoid personality disorder") AND ("suicide" or "suicidal" or "suicid"). The search included all languages. Fifty-three articles were identified. We excluded 39 articles, because they were studies unrelated to the topic. Further relevant articles were searched in the authors' personal files and in Google Scholar. Three studies were added after reference-checking, resulting in a final set of 17 articles in which a role of SZPD or traits is discussed (Table 1). We are clearly aware that - given the abovementioned literature search strategies - coverage may not be optimal: only Pubmed was consulted, thus missing non-biomedical literature.

\section{RESULTS AND CONCLUSIONS}

Reported studies show that an underlying SZPD, or the presence of schizoid traits too, appear to be definitely a major risk factor for completed suicide and serious suicide attempts. This maladaptive personality disorder seems to not allow the individual to ask for help and to deny him the comforts of intimacy (Horesh et al. 2012). Furthermore, individuals with SZPD or traits tend to plan their suicide attempt, enhancing its lethal potential (Gvion et al. 2014).

In particular, findings from this mini-review suggest that clinicians should be aware that schizoid traits suchs as solitary lifestyle, loneliness, emotional detachment, and impaired communication ability (e.g. poor selfdisclosure), are features associated with a vulnerability to suicidal behavior. Therefore, we recommend the clinical assessment of this symptoms' constellation, in order to address patients with SZPD to most proper treatment.

As for the management of SZPD symptoms, improving patient abilities of social communication - by interpersonal and supportive psychotherapy - should be an essential focus of treatment, in order to emphasize education and feedback concerning interpersonal skills and communication (Widiger \& Rojas 2015). Individual psychotherapy should focus on simple treatment goals to alleviate current troubling concerns or life stressors. Cognitive restructuring may be a way to address potential irrational thoughts and false perceptions. Also group therapy may be useful as a setting in which the patient can gradually develop self-disclosure, experience the interest of others, and practice social interactions with immediate and supportive feedback. Socialization groups and educational strategies in which individuals with SZPD identify their positive and negative emotions are generally recommended (Maass 2019). Psychopharmacological treatment of concomitant psychopathology should be also guaranteed. For example, antianxiety agents may be helpful during experiences of emotional tension or for interpersonal anxiety, (off-label) low-dose antipsychotics may reduce distorted thoughts, and serotonin reuptake inhibitors may be prescribed in cases of comorbid depression (Maass 2019, Widiger \& Rojas 2015). Finally, suicide-prevention plans should encourage helpseeking behavior (Levi-Belz et al. 2014).

Although the effectiveness of psychotherapeutic and pharmacological treatments for SZPD have yet to be systematically investigated (Maass 2019), we strongly believe that SZPD and its emotional and affective correlates are certainly treatable. In fact, individuals with SZPD are mostly untreatable because practitioners have not found adequate ways to engage and encourage them in the change process (Sperry 2016).

Lastly, we believe that more research is needed on the etiology and pathophysiology of SZPD. The pathology of SZPD is considered to be anhedonic deficits, or an excessively low ability to experience positive affect, which is also central to the general personality trait of introversion (Widiger \& Rojas 2015). It has been suggested that the personality dimension of introversion and greater tendencies toward social introversion during early adulthood may be substantial risk factors for suicidal behaviour (Roy 1998, Yen \& Siegler 2003). Therefore, further studies on the neurobiological underpinnings of anhedonia and introversion could help clarify the link between schizoid features and suicidality.

\section{Acknowledgements: None.}

\section{Conflict of interest: None to declare.}

\section{Contribution of individual authors:}

Luigi Attademo: design of the study, literature search and analysis, interpretation of data, manuscript writing;

Francesco Bernardini \& Roberta Spatuzzi: literature search and analysis.

All authors approval of the final version.

\section{References}

1. Akhtar S: Schizoid personality disorder: a synthesis of developmental, dynamic, and descriptive features. Am J Psychother 1987; 41:499-518. https://doi.org.10.1176/appi.psychotherapy.1987.41.4.499

2. American Psychiatric Association: Personality Disorders. In: Diagnostic and Statistical Manual of Mental Disorders. 5th ed, 645-684. Arlington, VA: American Psychiatric Publishing, 2013 
3. Apter A, Bleich A, King RA, Kron S, Fluch A, Kotler M et al.: Death without warning? A clinical postmortem study of suicide in 43 Israeli adolescent males. Arch Gen Psychiatry 1993; 50:138-42.

https://doi.org.10.1001/archpsyc.1993.01820140064007

4. Bolton JM, Pagura J, Enns MW, Grant B, Sareen J: A population-based longitudinal study of risk factors for suicide attempts in major depressive disorder. J Psychiatr Res 2010; 44: 817-26.

https://doi.org.10.1016/j.jpsychires.2010.01.003

5. Canal-Rivero $M$, Lopez-Moriñigo JD, Barrigón $M L$, Perona-Garcelán S, Jimenez-Casado C, David AS et al.: The role of premorbid personality and social cognition in suicidal behaviour in first-episode psychosis: A one-year follow-up study. Psychiatry Res 2017; 256:13-20. https://doi.org.10.1016/j.psychres.2017.05.050

6. Craig RJ \& Bivens A: MCMI-III Scores on Substance Abusers With and Without Histories of Suicide Attempts. Subst Abus 2000: 21: 155-61. https://doi.org.10.1080/08897070009511429

7. Del Bello V, Verdolini N, Pauselli L, Attademo L, Bernardini $F$, Quartesan $R$ et al.: Personality and psychotic symptoms as predictors of self-harm and attempted suicide. Psychiatr Danub 2015; 27: S285-91

8. Ellis TE, Rudd MD, Rajab MH, Wehrly TE: Cluster analysis of MCMI scores of suicidal psychiatric patients: four personality profiles. J Clin Psychol 1996; 52: 411-22. https://doi.org.10.1002/(SICI)1097-4679(199607)52:4 $<411: \because A I D-J C L P 5>3.0 . C O ; 2-S$

9. Fariba $K \&$ Gupta V: Schizoid Personality Disorder. StatPearls [Internet]. Treasure Island, FL: StatPearls Publishing, 2020. https://www.ncbi.nlm.nih.gov/books/NBK559234/

10. Gesi C, Carmassi C, Miniati M, Benvenuti A, Massimetti G, Dell'Osso L: Psychotic spectrum symptoms across the lifespan are related to lifetime suicidality among 147 patients with bipolar I or major depressive disorder. Ann Gen Psychiatry 2016; 15:15. https://doi.org.10.1186/s12991-016-0101-7

11. Goldney RD: Attempted suicide in young women: correlates of lethality. Br J Psychiatry 1981; 139: 382-90. https://doi.org.10.1192/bjp.139.5.382

12. Gupta SC \& Singh H: Psychiatric illness in suicide attempters. Indian J Psychiatry 1981; 23:69-74

13. Gvion Y, Horresh N, Levi-Belz Y, Fischel T, Treves I, Weiser $M$ et al.: Aggression-impulsivity, mental pain, and communication difficulties in medically serious and medically non-serious suicide attempters. Compr Psychiatry 2014; 55: 40-50. https://doi.org.10.1016/j.comppsych.2013.09.003

14. Horesh N, Levi Y, Apter A: Medically serious versus nonserious suicide attempts: relationships of lethality and intent to clinical and interpersonal characteristics. $J$ Affect Disord 2012; 136: 286-93. https://doi.org.10.1016/j.jad.2011.11.035

15. Lesage AD, Boyer R, Grunberg F, Vanier C, Morissette R, Ménard-Buteau $C$ et al.: Suicide and mental disorders: a case-control study of young men. Am J Psychiatry 1994; 151: 1063-68. https://doi.org.10.1176/ajp.151.7.1063

16. Levi-Belz Y, Gvion Y, Horesh N, Fischel T, Treves I, Or E et al.: Mental pain, communication difficulties, and medically serious suicide attempts: a case-control study. Arch Suicide Res 2014; 18: 74-87.

https://doi.org.10.1080/13811118.2013.809041

17. Levi-Belz Y, Gvion Y, Levi U, Apter A: Beyond the mental pain: A case-control study on the contribution of schizoid personality disorder symptoms to medically serious suicide attempts. Compr Psychiatry 2019; 90:102-9. https://doi.org.10.1016/j.comppsych.2019.02.005

18. Levi Y, Horesh N, Fischel T, Treves I, Or E, Apter A: Mental pain and its communication in medically serious suicide attempts: an "impossible situation". J Affect Disord 2008; 111: 244-50. https://doi.org.10.1016/j.jad.2008.02.022

19. Maass VS: Personality Disorders. Elements, History, Examples, and Research. Santa Barbara, CA: Praeger, 2019

20. Masterson JF \& Klein R: Disorders of the self - The Masterson approach. New York, NY: Brunner/Mazel, 1995

21. McCann JT \& Suess JF. Clinical applications of the MCMI: the 1-2-3-8 codetype. J Clin Psychol 1988, 44: 181-6. https://doi.org.10.1002/1097-4679(198803)44:2< 181::aid-jclp2270440214>3.0.co;2-i

22. Morgan TA \& Zimmerman M: Epidemiology of Personality Disorders. In: Livesley WJ \& Larstone R (eds.), Handbook of Personality Disorders. Theory, Research, and Treatment. 2nd ed, 173-96. New York, NY: Guilford Press, 2018

23. Oldham JM, Skodol AE, Bender DS: The American Psychiatric Publishing textbook of personality disorders. 2nd ed. Washington, DC: American Psychiatric Publishing, 2014

24. Pompili M, Rihmer Z, Akiskal HS, Innamorati M, Iliceto $P$, Akiskal KK et al.: Temperament and personality dimensions in suicidal and nonsuicidal psychiatric inpatients. Psychopathology 2008; 41:313-21. https://doi.org.10.1159/000146069

25. Roy A: Is introversion a risk factor for suicidal behaviour in depression? Psychological Medicine 1998; 28: 145761. https://doi.org.10.1017/s0033291798007028

26. Sperry L: Handbook of Diagnosis and Treatment of DSM-5 Personality Disorders: Assessment, Case Conceptualization, and Treatment. 3rd ed. New York, NY: Routledge, 2016

27. Widiger TA \& Rojas SL: Personality disorders. In Tasman $A$, Kay J, Lieberman JA, First MB, Riba MB (eds.): Psychiatry. 4th ed. Vol. 2, 1706-48. Hoboken, NJ: WileyBlackwell, 2015

28. Wolff S: Psychiatric morbidity and criminality in 'schizoid' children grouwn-up: A records survey. Eur Child Adolesc Psychiatry 1992; 1:214-21. https://doi.org.10.1007/BF02094181

29. Yen $S$ \& Siegler IC: Self-Blame, Social Introversion, and Male Suicides: Prospective Data from a Longitudinal Study. Arch Suicide Res 2003; 7:17-27. https://doi.org/10.1080/13811110301569

\section{Correspondence:}

Luigi Attademo, $M D$

Psychiatric Inpatient Unit at San Carlo Hospital of Potenza, Department of Mental Health,

ASP Basilicata, Via Petrone, 85100 Potenza, Italy

E-mail: luigi.attademo@hotmail.it 